ISSN: $2219-8229$

E-ISSN: 2224-0136

Founder: Academic Publishing House Researcher

DOI: $10.13187 /$ issn. $2219-8229$

Has been issued since 2010 .

European Researcher. International Multidisciplinary Journal

UDC 621.31

\title{
Development of Gas Turbine Fast Mathematical Model Simulation Module for Software Complex «Electrodin» based on LabVIEW*
}

\author{
${ }^{1}$ Olga A. Iarmonova \\ ${ }^{2}$ Anton B. Petrochenkov \\ ${ }^{3}$ Bernd Krause
}

\begin{abstract}
1Perm National Research Polytechnic University, Russian Federation
Professora Pozdeyeva 7, Perm, 614013,

E-mail: seitsemas07@rambler.ru

2Perm National Research Polytechnic University, Russian Federation

Professora Pozdeyeva 7, Perm, 614013,

E-mail: pab@msa.pstu.ac.ru

${ }^{3}$ Anhalt University of Applied Sciences, Germany

Postfach 1458, 06354 Koethen (Anhalt)

E-mail: bernd.krause@inf.hs-anhalt.de
\end{abstract}

Abstract. A fast mathematical model simulation module based on LabVIEW graphical programming environment has been developed. The module will be used for gas turbine and electrical power system co-simulation, and for testing automation of gas turbine automatic control systems.

Keywords: computer simulation; gas turbine; automatic control system; electrical power system; fast mathematical model; LabVIEW.

\section{Introduction}

Nowadays there is a growing demand for highly efficient gas turbines units (GTU) in energy and oil and gas industries to achieve economic efficiency and low environmental impact. A gas turbine engine is used in a broad scope of applications including electric power generation (to drive an electric generator), natural gas transmission (to drive pumps and compressors), and various process applications. The main advantages of modern gas turbines include compact size, ecological compatibility, relatively low capital investment, ability to work in cogeneration and trigeneration modes.

This work was carried out within the framework of the project which purpose was to create a multi-adaptive ecological test rig for gas turbines up to $40 \mathrm{MW}$ for such objects as gas pumping units (GPU) and gas turbine power plants. The main goal was to increase GTU and GPU testing efficiency by development of the fast mathematical model simulation module based on LabVIEW

\footnotetext{
${ }^{*}$ From 23.06.2013 on 01.07.2013 Perm National Research Polytechnic University (PNRPU) in collaboration with the University of Applied Sciences (UAS) Anhalt (Germany) held an International summer school "Information Management". During the school were conducted master classes by leading professors of UAS Anhalt, UAS Hamburg, PNRPU, Bauman Moscow State Technical University. Perm and German universities' students enrolled in the "double degree" program, presented papers on the subject of research at the partner universities. The best 3 papers are presented in this journal.
} 
for gas turbine, gas turbine automatic control system (ACS) and electrical power system cosimulation.

\section{Automation of Gas Turbine Testing}

The current situation in the field of GTU test automation is undergoing a lot of changes due to the expansion of their range of use, and, therefore, with the constant increase in the requirements for their operation and function. The specifics of GTU operation in new conditions as the drive for electric generator requires formation of new control algorithms, as well as conduction of research to reveal the impact on the quality of the transient processes during various modes of operation of the power plant, which includes gas turbines.

Also, there is significant progress in the development of software and hardware for automation devices, computing techniques, and information technologies. This provides the basis for GTU testing process modernization.

There are three types of GTU testing:

1) computer simulation;

2) semi-realistic simulation;

3) full-scale testing.

Let us consider the existing technology of GTU testing [1].

At first, tests are conducted on a computer (computer simulation), where hardware is simulated by mathematical models.

After that GTU software is checked by semi-realistic simulation using the microprocessors supplied by the developers and suppliers of hardware. Computer based model of GTU integrates with full-scale control equipment. Semi-realistic simulation enables to study control system functioning, and to assess the effectiveness of a complex control system in conditions as close to real as possible.

After the successful completion of the previous steps full-scale tests are carried out. Fully equipped gas turbine pilot unit is placed on a special testing rig for its trial in various modes of operation. GTU loading is carried out by a hydraulic brake, load of the field of active resistance or a power generator.

It should be noted that gas turbine operates only in the presence of ACS, which is a combination of a GTU and control devices. ACS is designed to perform the functions of control, monitoring and protection, ensuring long trouble-free operation of the unit. The controller contains ACS algorithms, which control the operation of gas turbine in various modes. Therefore, gas turbine testing is accompanied by gas turbine ACS testing.

Usually, when full-scale GTU ACS test begins parameters and control algorithms are already chosen by the developer of ACS. However, there is possibility to adjust the control algorithm by changing the preset ratios within a limited range. Adjustment is performed for each GTU separately and its results accompany the unit throughout its life cycle. Therefore, adjustment operation of ACS is essential for achieving high operational performance of GTU ACS.

Types of GTU tests mentioned above differ in the cost of research and in the possibilities of technical equipment, and mainly in the creation of conditions and ranges of factors influence that determine the functioning of GTU.

Practice shows that GTU testing types differ little in the possibilities of obtaining reliable characteristics of gas turbines, thus the amount of work and testing costs can be reduced for semirealistic simulation and full-scale tests on the tasks that have been confirmed by computer simulation.

The benefits of computer and semi-realistic simulation are:

1) ability to reproduce the entire set of subcritical modes;

2) economic efficiency (fuel economy, lower material costs and cost by time);

3) flexibility of testing programs (possibility of conducting a large number of different testing programs);

4) ample opportunities for processing test results;

5) absence of risk of process upsets and equipment damage due to improper control commands.

Ample opportunities are provided in the application of combination of semi-realistic simulation and full-scale tests of ACS. This allows to make a system of mutually-complementary 
tests, where ACS setting will be made during semi-realistic simulation, and the final ACS adjustment will be made during full-scale tests.

It should be noted that one of the main disadvantages of existing GTU testing technology is the lack of information about electrical power system operation modes in which GTU should operate. Tests with electrical power system are fulfilled only in part by full-scale tests on the testing rigs with limited functionality. The behavior of electrical load during the design stage, testing and adjustment of GTU ACS algorithms is important for GTU operating in the gas turbine power plant, therefore, information about electrical power system operation modes should be taken into account during computer and semi-realistic simulation of gas turbines.

Gas Turbine Computer Simulation

Overall, there are two classes of mathematical models used for GTU testing:

1) simplified mathematical models;

2) complete mathematical models (verification models).

Complete mathematical models are usually used in the last steps of GTU testing and simplified mathematical models are used for the calculation and modeling steps. Simplified mathematical models provide exact solution with the assumptions made. This solution can be used as a base for the implementation of the following steps.

GTU under consideration may consist of a large number of elements, so that even the use of modern computer technologies would require significant time for model calculation. Also, there are difficulties in conducting semi-realistic simulation, as it has more stringent requirements for models operation speed: models have to work at a pace of the real tested object.

Therefore, fast calculated mathematical models were used to configure ACS GTU algorithms, and for computer and semi-realistic testing of control algorithms. Fast mathematical models are built on the basis of simplified identification nonlinear models of gas turbines.

The main idea of fast mathematical models is to combine the linear dynamic model and nonlinear static characteristics of GTU. This type of mathematical models can ensure accuracy in the range of 2 - 5\% [2] and provides significant calculation time savings.

Fast mathematical models can be obtained by measuring the operating parameters of a fullscale GTU which is designed for use in a gas turbine power plant or GPU. Results of simulation with nonlinear dynamic GTU model can be used instead of the data from the full-scale gas turbine when debugging identification algorithms and before transferring algorithms to the real object.

The following fast mathematical models were implemented in this work:

1) linear gas turbine unit model;

2) nonlinear gas turbine unit model;

3) nonlinear gas pumping unit model;

4) nonlinear Capstone microturbine model (Capstone C-30);

5) electrical power system model;

6) gas turbine automatic control system model.

Below is a mathematical description of one of the GTU models.

Nonlinear Gas Pumping Unit Model

Fast mathematical model is designed to provide gas pumping unit control systems adjustment procedure. The model takes into account the accumulation of energy in the rotating mass of the two-shaft gas turbine rotor.

$$
\begin{aligned}
& \dot{\mathrm{A}}_{\mathrm{DI}}=\frac{\left(\mathrm{A}_{\mathrm{DIZ}}-\mathrm{A}_{\mathrm{DI}}\right)}{\mathrm{T}_{\mathrm{DI}}}, \\
& \mathrm{G}_{\mathrm{TS}}=f\left(\mathrm{~A}_{\mathrm{DI}}\right), \\
& \dot{\mathrm{G}}_{\mathrm{T}}=\frac{\left(\mathrm{G}_{\mathrm{TS}}-\mathrm{G}_{\mathrm{T}}\right)}{\mathrm{T}_{\mathrm{GT}}}, \\
& \mathrm{n}_{\mathrm{TS}}=f\left(\mathrm{G}_{\mathrm{T}}\right), \\
& \dot{\mathrm{n}}_{\mathrm{TK}}=\frac{\left(\mathrm{n}_{\mathrm{TS}}-\mathrm{n}_{\mathrm{TK}}\right)}{\mathrm{T}_{\mathrm{NTK}}},
\end{aligned}
$$




$$
\begin{aligned}
& \mathrm{N}_{\mathrm{E}}=f\left(\mathrm{n}_{\mathrm{TK}}\right), \\
& \mathrm{n}_{\mathrm{CTZ}}=f\left(\mathrm{~N}_{\mathrm{E}}\right), \\
& \mathrm{n}_{\mathrm{CT}}^{*}=\frac{\left(\mathrm{n}_{\mathrm{CTZ}}-\mathrm{n}_{\mathrm{CT}}\right)}{\mathrm{T}_{\mathrm{NCT}} \mathrm{n}_{\mathrm{CT}}},
\end{aligned}
$$

where $A_{D I Z}$ is specified gas regulator rotation angle, $A_{D I}$ is gas regulator rotation angle, $G_{T}$ is fuel consumption, $\mathrm{G}_{\mathrm{TS}}$ is fuel consumption based on the static characteristic, $\mathrm{n}_{\mathrm{TS}}$ is compressor rotor speed based on the static characteristic, $\mathrm{n}_{\mathrm{TK}}$ is compressor rotor speed, $\mathrm{N}_{\mathrm{E}}$ is available power of free power turbine, $\mathrm{n}_{\mathrm{CT}}$ is free power turbine rotor speed, $\mathrm{n}_{\mathrm{CTZ}}$ is free power turbine rotor speed based on the static characteristic, $\mathrm{n}_{\mathrm{CT}}$ is free power turbine rotor speed, $\mathrm{T}_{\mathrm{DI}}$ is gas regulator time constant, $\mathrm{T}_{\mathrm{GT}}$ is fuel consumption time constant, $\mathrm{T}_{\mathrm{NTK}}$-is compressor rotor time constant, $\mathrm{T}_{\mathrm{NCT}}$ is free power turbine rotor time constant.

\section{Electrical Power System Model}

Fast mathematical model of electrical power system can be implemented in two versions: fast mathematical model of the entire power system; fast mathematical model of an element or a subsystem of electrical power system. This provides the necessary flexibility.

The main disturbance from electrical power system is the active power which is converted into mechanical power on the shaft of gas turbine. In the case of multiply connected systems, it is required to take into account the voltage changing at the nodal points of electrical power system. Therefore, fast mathematical models used for simulation are considered relative to the active power and voltage. The scheme of the model is shown in Figure 1 where SG is synchronous generator, AFR\&E is automatic field regulator and exciter [4].

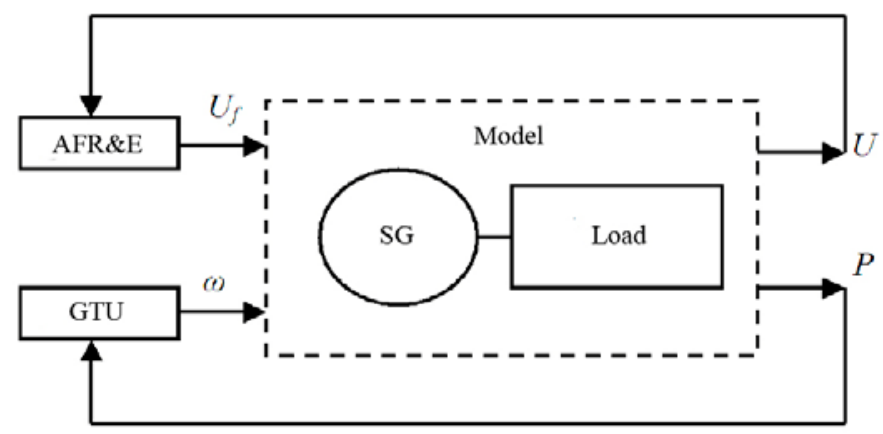

Fig. 1. The scheme of the fast mathematical model which is considered relative to the active

Electrical power system model is as follows [2]: power and voltage

$$
\mathbf{V}(\mathrm{k}+1)=\mathbf{A V}(\mathrm{k})
$$

where $\mathbf{V}(\mathrm{k})$ is the extended state vector for $\mathrm{k}$ moment, $\mathbf{V}(\mathrm{k}+1)$ is the extended state vector for $(\mathrm{k}+1)$ moment, $\mathbf{A}$ is the transition matrix from state at $\mathrm{k}$ moment to the new state at $(\mathrm{k}+1)$ moment.

Since electrical power system is a nonlinear object with structurally complex model sometimes it is necessary to use several matrices $\mathbf{A}$ or a matrix $\mathbf{A}$ with variable parameters which are functions of the operating mode and operating parameters [1].

In the used model of electrical power system the following operational parameters are taken into consideration: load power, generator rotation frequency, generator voltage, generator excitation voltage, generator current and generator field current. These parameters are written in the state vector of the system $\mathbf{V}$.

Gas Turbine Automatic Control System Model

Automatic control system of fuel regulator has a complex structure. Therefore, in this work, free power turbine speed stabilization loop is considered to simplify this problem. This loop is basic and it defines free power turbine speed error by set point.

Real-life GTU free power turbine speed regulator is taken as a basis. The linearized simplified regulator structure is shown in Figure 2. 


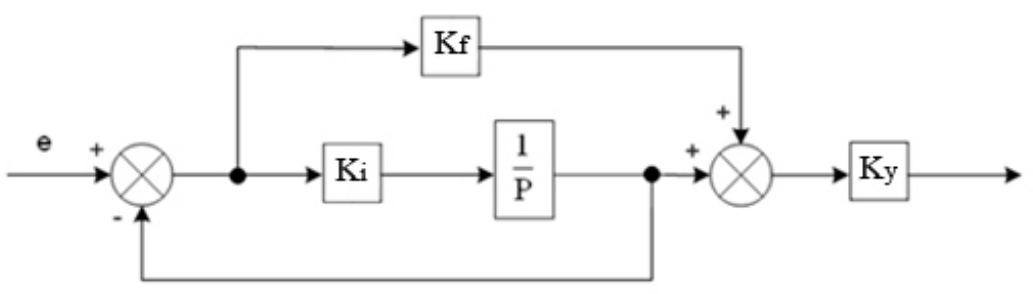

Fig. 2. Regulator schematic diagram

Aperiodic link of the regulator is formed by the coverage of the integrator by negative feedback. Forcing link of the regulator is formed by parallel chains of the integrator and a chain with a forcing component gain $\mathrm{K}_{\mathrm{f}}$.

In real regulators all parameters $\mathbf{K}=\left(\mathrm{K}_{\mathrm{i}}, \mathrm{K}_{\mathrm{y}}, \mathrm{K}_{\mathrm{f}}\right)^{\mathrm{T}}$ are the functions of GTU operating mode because it is necessary to take into account the nonlinearity of the control object.

The difference between the setpoint and the actual value of the free power turbine speed is determined by the formula (10).

$$
\mathrm{e}=\mathrm{n}_{\mathrm{cT}}^{\text {stpnt }}-\mathrm{n}_{\mathrm{cr}}
$$

Regulator transfer function is as follows:

$$
W(p)=e \cdot\left(\frac{1}{T_{i^{\prime} p+1}}+K_{f}\right) \cdot K_{y}
$$

where $\mathrm{T}_{\mathrm{i}}=\frac{1}{\mathrm{~K}_{\mathrm{i}}} ; \mathrm{K}_{\mathrm{f}}$ is forcing component of free power turbine loop gain; $\mathrm{K}_{\mathrm{y}}$ is free power turbine loop gain; $K_{\mathrm{i}}$ is integral component of free power turbine loop gain.

Software Complex "ElectroDin" for Gas Turbine Unit and Gas Turbine Unit Automatic Control System Testing

Software complex "ElectroDin" is used to make fast mathematical models. It is written in the J ava programming language [5, 6].

Software complex "ElectroDin" is designed for gas turbine testing, for GTU ACS adjustment and testing on a simulation multimode dynamic model of electrical power system, for steady and transient state calculation and for calculation of processes in electrical power system of any structure, as well as for GTU models identification.

To obtain the desired gas turbine mathematical model required parameters selection is carried out for model identification based on experimental data. After that, mathematical model identification is performed and mathematical model adequacy is checked. The obtained model parameters are stored in a XML file format. The results of gas turbine identification are coefficient values of differential equations of the model and static characteristics.

Module for complete electrical power system mathematical model simulation is designed for reproduction of dynamic operation modes on the mathematical model to solve problems of analysis which involve process calculation (electromagnetic, mechanical, etc.) in a given electrical power system. Electrical power system has a predetermined structure and characteristics of all its elements.

Mathematical model of electrical power system consists of two interrelated components: model of individual elements and their interaction model.

Universality of algorithms for computing is achieved by presenting all models of the elements in a single generalized form:

1) the mathematical model of each structural element is represented in the Park-Gorev coordinates and is written in the form of a system of differential equations;

2) the mathematical models of elements are transformed to a single generalized matrix-vector form.

For steady state matrix-vector equation is as follows [7]: 


$$
\mathbf{U}= \pm \mathbf{A} \times \mathbf{I}+\mathbf{E},
$$

where $\mathbf{U}$ is terminal voltage column matrix for $\mathrm{d}$, q axes; $\mathbf{A}$ is resistance of the element matrix for d, q axes; I is current of the element column matrix for d, q axes; $\mathbf{E}$ is voltage source of the element column matrix for $\mathrm{d}$, $\mathrm{q}$ axes.

For transient state matrix-vector equation is as follows [7]:

$$
\mathrm{pI}= \pm \mathbf{A U}-\mathbf{B I}-\mathbf{H},
$$

where $\mathbf{~ I}, \mathbf{I}$ are current vector and vector of current derivatives of the element; $\mathbf{U}$ is vector of voltage applied between the external terminals of the element; $\mathbf{A}, \mathbf{B}$ are matrices which dimension depends on the coordinate system in which the structural element is simulated, also it depends on the equation form (full form or simplified form); $\mathbf{H}$ is vector which determines the impact of electrical parameters control means on the element; $p$ is symbol of differentiation.

For electrical power system parameters calculation node voltage method is applied. Node voltages are found from the following system of equations [7]:

$$
\boldsymbol{Y} \times \boldsymbol{U}=\boldsymbol{J},
$$

where $\mathbf{Y}$ is block matrix of known nodal conductivity; $\mathbf{U}$ is block-column matrix of nodal voltages; J is block-column matrix of known setting currents.

Defined nodal voltages are used to calculate currents for each of the elements. After that, all other parameters are calculated.

Fast mathematical model of electrical power system is a separate mode of software complex "ElectroDin". It is used for automatic adjustment of GTU ACS. To construct the fast mathematical model of electrical power system arrays of experimental data of established transient state are used. In this case the presence of array of an active power and generator speed is required. Moreover, the more additional variables are in the experimental data, the more accurate model is obtained. Additional variables can be taken from different elements of electrical power system.

To obtain the required fast mathematical model of electrical power system simulation of the desired mode on the full model is performed. Then the obtained dependencies of the parameters from the transient state time are stored. After that, selection of the main parameters of the structural elements which have most influence on the mode process is performed. Then these parameters (time, active power of the generator, generator speed, etc.) are collected in one file. Fast mathematical model is created by running the module for fast mathematical model construction where the model is identified and checked.

The output of the fast mathematical model module is:

1) the coefficient matrix of the model in the state space;

2) the state vector of the initial steady state;

3) the state vector of the beginning of the transition process.

The obtained model of electrical power system is written in the CSV file which data is used for GTU load model.

Structure of the software complex "ElectroDin" is shown in Figure 3. 


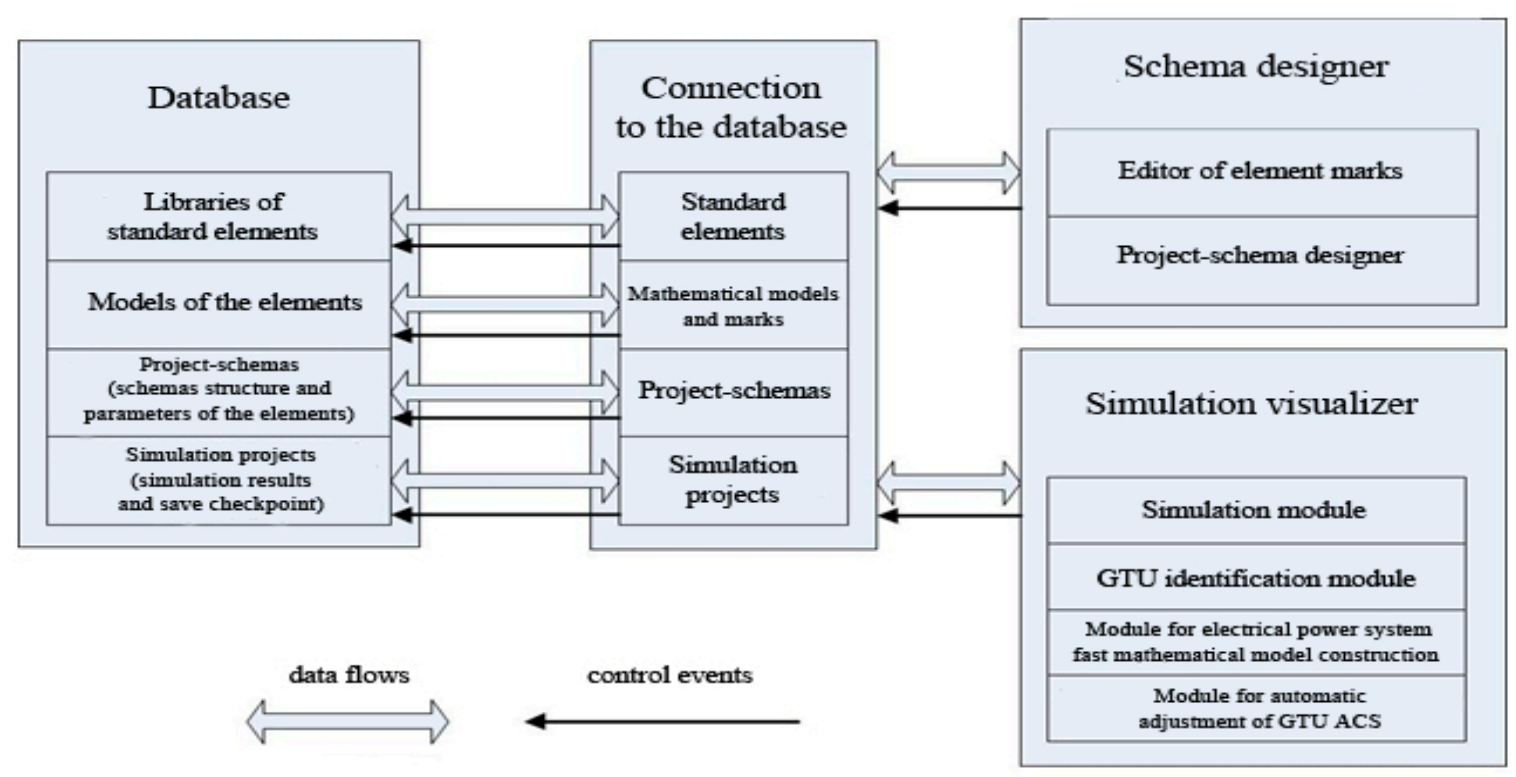

Fig. 3. Structure of the software complex "ElectroDin" and relationship between its components

Since the software complex "ElectroDin" is unable to work in real time it was necessary to create an additional simulation module using tools which enable to solve this problem.

\section{Simulation Module for Software Complex «ElectroDin» based on LabVIEW}

When creating specialized software the need to choose one of the following ways arises:

1) the use of traditional programming tools (traditional programming languages, standard debugging tools, etc.);

2) the use of existing development tools best suited to achieve the objectives and requirements which are imposed for software.

The most important tasks are as follows: reducing the time and cost of software development; minimizing the complexity associated with debugging and simulation of mathematical algorithms that are needed to obtain intermediate and final results and measurements.

For complex distributed systems development process of their own software using traditional programming tools may become too time-consuming and costly. This way is suitable mainly for simple systems or elements of a larger system for which there are no standard solutions or these solutions are not satisfied for some reason or other.

When some specific software development environment is selected, it must meet all the requirements which are imposed for the programming language and support all modern standard communication protocols, and also, it must have high compatibility with other programming languages.

In our case, the second way was preferred, as it was required to minimize the time needed to develop a module, to debug it and to simulate mathematical algorithms. Also, it was required to provide the ability to support standard communication protocols and to achieve a high compatibility with other programming languages and hardware.

In this work, LabVIEW graphical programming environment was chosen for module development. Selection of LabVIEW as a mean of module implementation is due to the fact that this environment is used in automation testing rigs of Perm engine company [8]. Also, choice of LabVIEW is explained by the following reasons:

1) environment provides the requirement of cross-platform;

2) environment provides high performance by enabling data acquisition and data processing in real time and by enabling testing in parallel mode;

3) environment provides flexibility and extensibility of developed applications by using the concept of modular programming;

4) environment provides accuracy of the calculations.

The basis of National Instruments measurement and control systems is the concept of virtual instruments (VIs) which are the measurement tools built on the basis of computer technology, data 
acquisition boards and software for data acquisition and processing [9]. As the functionality of virtual instruments is programmed by the user, they are extremely flexible and efficient.

Description of Simulation Module

As it was said before, following fast mathematical models which were obtained using software complex "ElectroDin" were implemented in the module based on LabVIEW: linear and nonlinear GTU models, nonlinear gas pumping unit model, nonlinear Capstone microturbine model, electrical power system model, and gas turbine ACS model.

Parameters of specified fast mathematical models are obtained using software complex "ElectroDin", and then put in a simulation module based on LabVIEW via CSV and XML file formats. The result of modeling is a set of basic parameters dependencies from the time of transient state.

Figure 4 shows the connection between software complex "ElectroDin" and module based on LabVIEW.

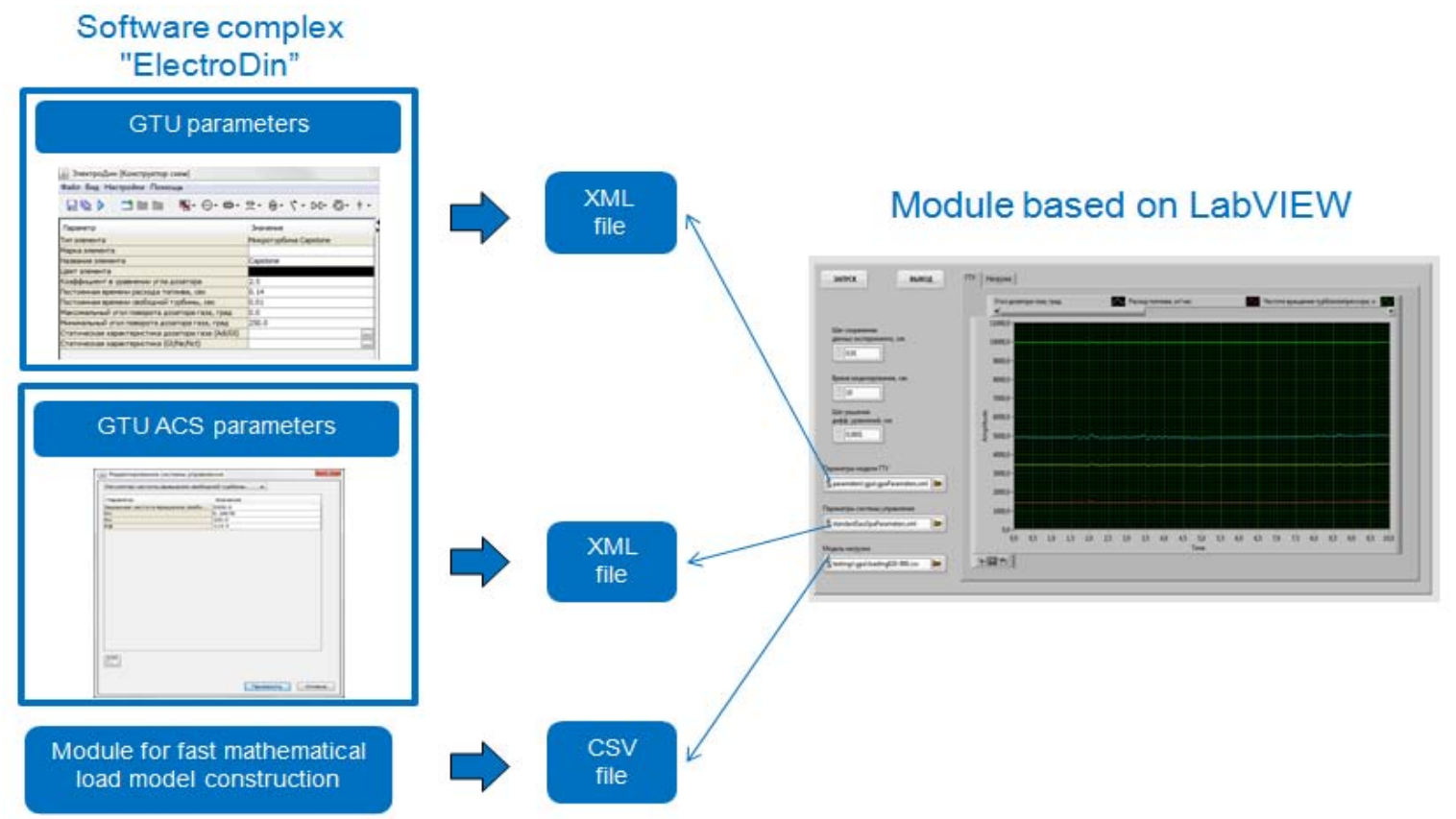

Fig. 4. Connection between software complex "ElectroDin" and module based on LabVIEW.

Front panel of the module is shown in Figure 5.

Simulation settings of the module include:

1) data saving step time is the interval with which the module saves parameters and displays them in the form of graphs after simulation has ended. Data saving step time affects the accuracy of the display of the parameters;

2) simulation time is the total simulation time;

3) step time of differential equations solving is the interval with which module solves differential equations. This parameter affects the accuracy of the transient state calculation.

Initial parameters which were obtained using software complex "ElectroDin" include:

1) GTU model parameters (XML file with values of coefficients and constants of GTU, and static characteristics);

2) GTU ACS parameters (XML file with values of coefficients of GTU ACS, and static characteristics);

3) Load model (CSV file with values of parameters and coefficients of electrical power system). 


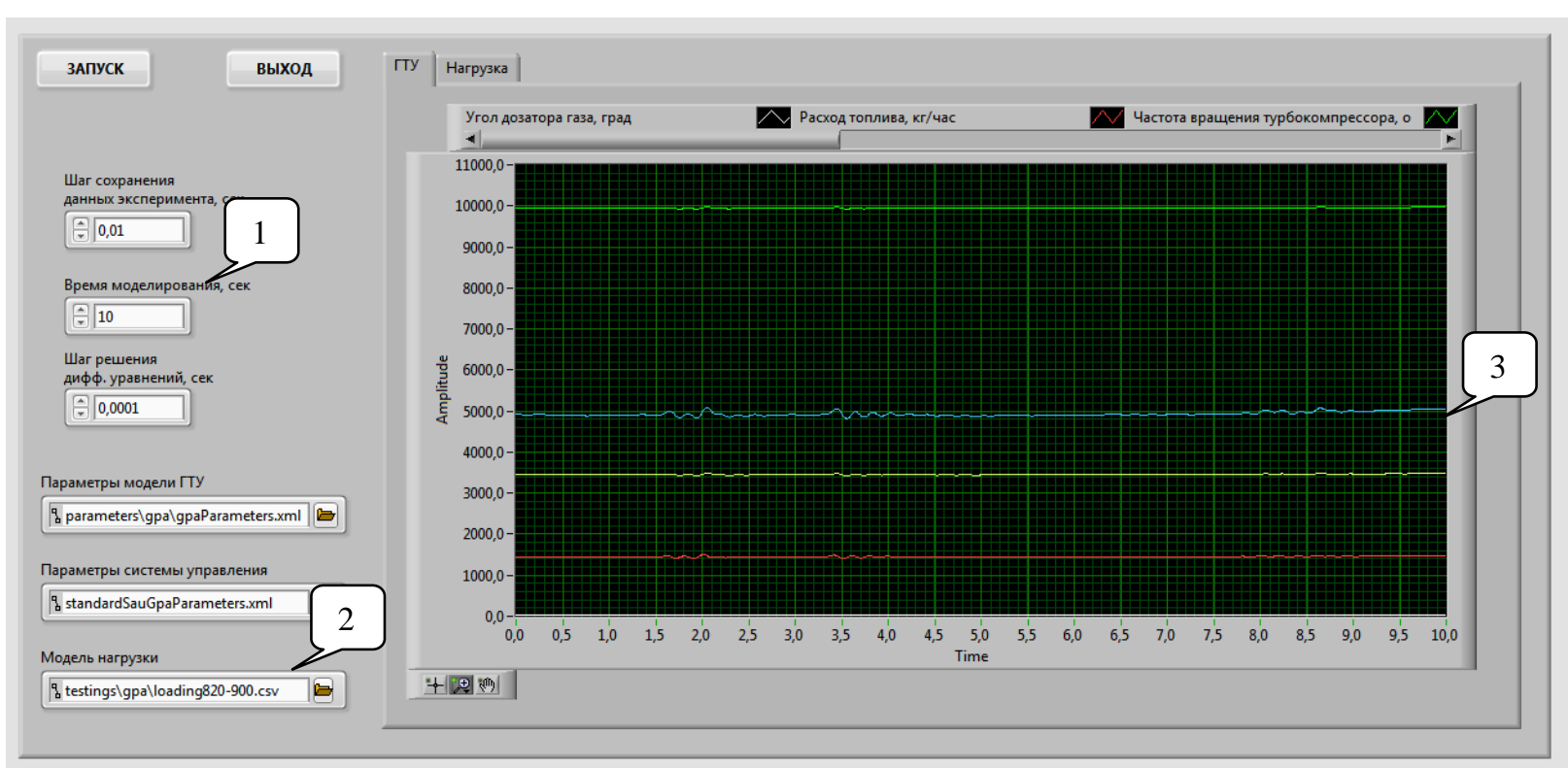

Fig. 5. Front panel of the simulation module based on LabVIEW:

1 - simulation settings; 2 - files with the initial parameters of GTU,

GTU ACS and load models; 3 - dependencies of main mathematical model parameters from the time of the transient state

The module is based on the concept of modular programming. A large problem was divided into a series of simple subtasks. Then VIs to perform each of the subtasks were created, and combined on the Block Diagram of higher level application which performs the task as a whole.

The advantage of modular programming technology is the ability to work with each SubVI separately making it easier to debug the module as a whole. Besides some SubVIs of a low level often perform tasks that are typical for several SubVIs of a higher level, and therefore can be used independently a lot of times.

The project includes thirty main VIs and SubVIs. On the basis of the set of interchangeable VIs the user can write his own GTU models, load models (electrical power system models) and GTU ACS models.

Description of the Modeling Order

The module consists of two subprograms:

1) subprogram for testing GTU model without GTU ACS;

2) subprogram for testing GTU model with GTU ACS.

The simulation runs as follows:

1) place required GTU model into corresponding directory;

2) launch simulation subprogram;

3) select files with initial parameters of GTU, GTU ACS and load models;

4) select data saving step time, simulation time and step time of differential equations solving;

5) start the simulation by clicking "Запуск" ("Start") button.

After the simulation, the right pane displays the dependencies of the main GTU parameters and load parameters from the time of the transient state. It is possible to record the parameters values in XLS file.

Figure 6 shows general algorithm of the module for gas turbine, gas turbine ACS and electrical power system co-simulation, where $T_{s}$ is the simulation time and $T_{\text {de }}$ is the step time of differential equations solving.

As it can be seen from Figure 6, mathematical modeling is divided into two classes:

1) mathematical models for steady state calculation (static mode calculation);

2) mathematical models for transient state calculation (dynamic mode calculation).

The main task of the developed module is reproduction of dynamic modes of GTU operation on mathematical model for the purpose of making an investigation and GTU control. But transient 
processes start with prior steady states, therefore, static mode should be calculated first, and then the dynamic mode.

The interaction between mathematical models of GTU, GTU ACS and electrical power system is carried out due to the transmission of parameters such as power consumption, gas regulator rotation angle, free power turbine rotor speed.

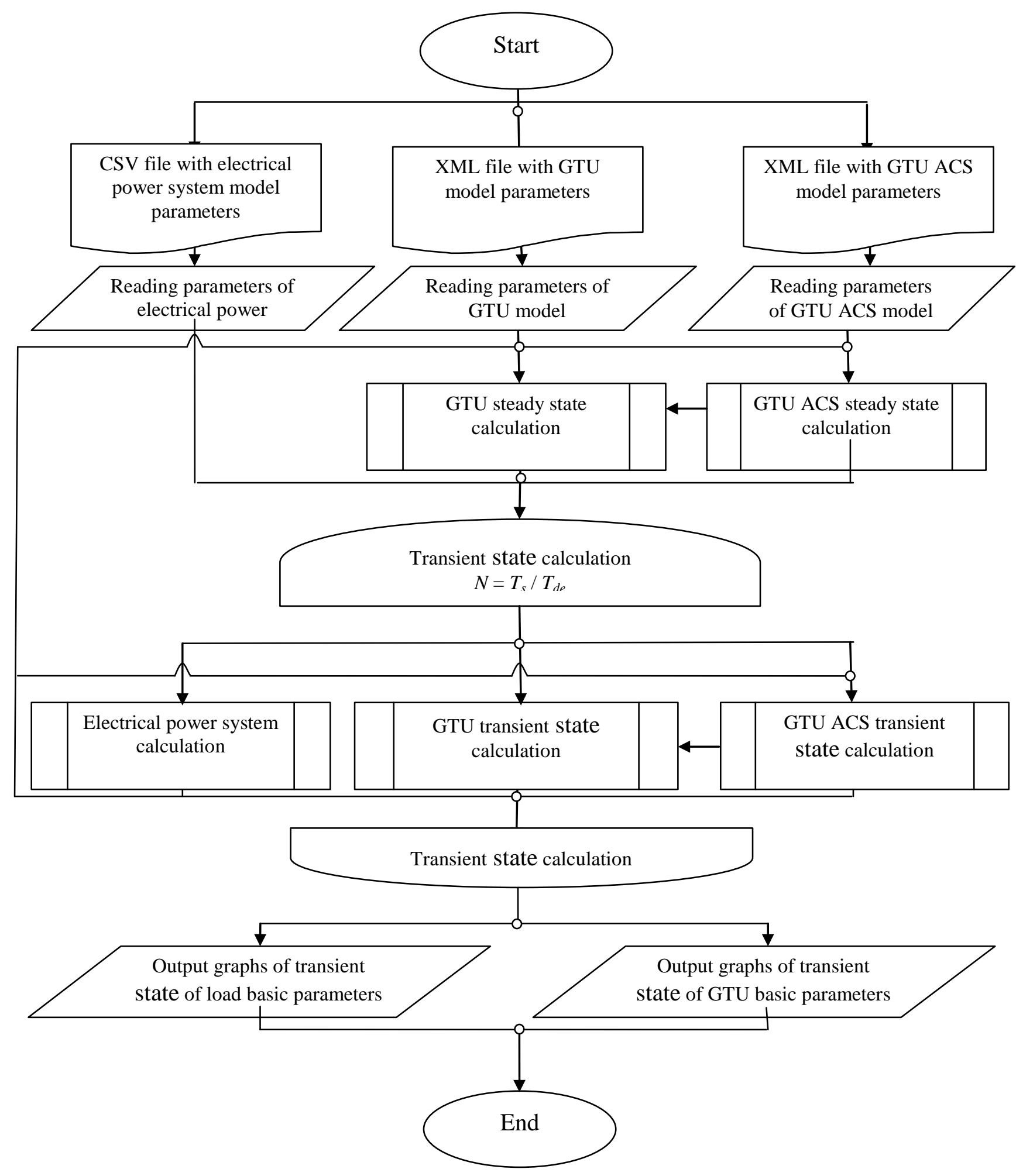

Fig. 6. The algorithm of gas turbine, gas turbine automatic control system and electrical power system co-simulation 


\section{Results and Discussion}

In this study, assessment of the quality and accuracy of the gas turbine simulation was performed by using the Theil uncertainty coefficient: implemented fast mathematical models were evaluated by comparing simulation results with sets of experimental data obtained in real gas turbine testing.

Theil uncertainty coefficient U measures the degree of discrepancy between the values of the generalized process parameter determined experimentally and the values of the generalized process parameter determined by calculation according to the model [10, 11].

$$
\mathrm{U}_{1}=\frac{\sqrt{\frac{1}{\mathrm{~N}} \sum_{\mathrm{i}=1}^{\mathrm{n}}\left(\mathrm{x}_{\mathrm{i}}^{(\mathrm{e})}-\mathrm{x}_{\mathrm{i}}^{(\mathrm{m})}\right)^{2}}}{\sqrt{\frac{1}{\mathrm{~N}} \sum_{\mathrm{i}=1}^{\mathrm{n}}\left(\mathrm{x}_{\mathrm{i}}^{(\mathrm{e})}\right)^{2}}+\sqrt{\frac{1}{\mathrm{~N}} \sum_{\mathrm{i}=1}^{\mathrm{n}}\left(\mathrm{x}_{\mathrm{i}}^{(\mathrm{m})}\right)^{2}}},
$$

where $\mathrm{x}_{\mathrm{i}}(\mathrm{e})$ is experimental value, $\mathrm{x}_{\mathrm{i}}{ }^{(\mathrm{m})}$ is the value calculated by the functional model, $\mathrm{n}$ is the number of experimental values which were used for the model synthesis.

The values of the Theil uncertainty coefficient belong to the interval [0,1]. Ends of the interval have the following interpretation: if the Theil coefficient is $U=0$ then we have a perfect fit; if the Theil coefficient is $U=1$ then model is inadequate [12].

Acceptable error of the model is determined by the error of measuring instruments. The model must have an error of no more than 1-2\% [4].

Figure 7 shows dependencies of fuel consumption $\mathrm{G}_{\mathrm{T}}$ from the time of the transient state, compressor rotor speed $\mathrm{n}_{\mathrm{TK}}$ from the time of the transient state, free power turbine rotor speed $\mathrm{n}_{\mathrm{CT}}$ from the time of the transient state, gas regulator rotation angle $A_{D I}$ from the time of the transient state, available power $\mathrm{N}_{\mathrm{E}}$ from the time of the transient state which were obtained during step increase load simulation of gas pumping unit model. Figure 8 shows dependency of active power from the time of the transient state.

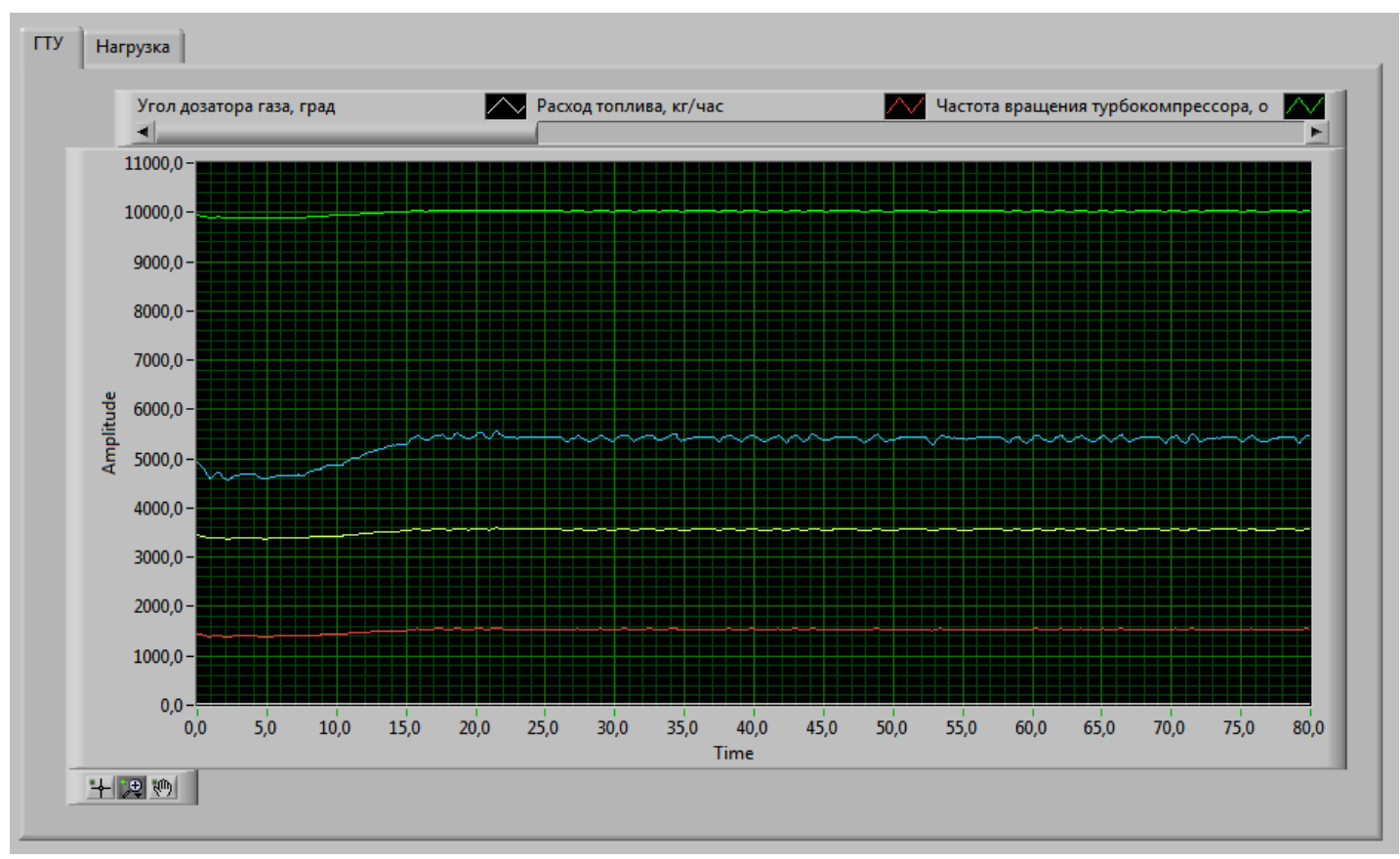

Fig. 7. Dependencies of $G_{T}, n_{T K}, n_{C T}, A_{D I}, N_{E}$ from the time of the transient state which were obtained during step increase load simulation of gas pumping unit model 


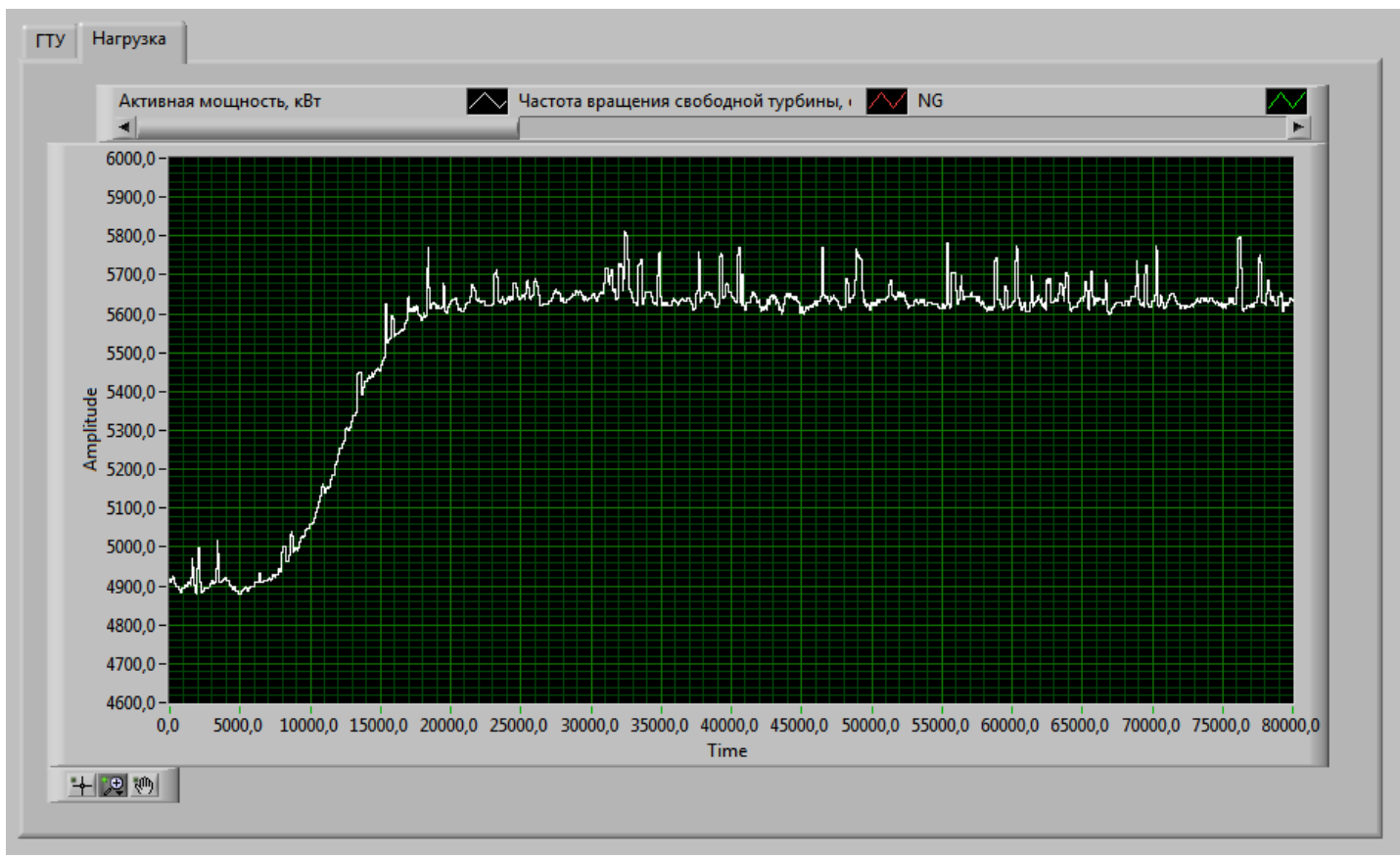

Fig. 8. Dependency of active power from the time of the transient state which was obtained during step increase load simulation of gas pumping unit model

Figures 9, 10 and 11 show dependencies of compressor rotor speed, free power turbine rotor speed and fuel consumption from the time of the transient state which were obtained experimentally and during simulation. The study was conducted by putting gas regulator rotation angle experimental values and load power experimental values to the gas pumping unit model input. The experimental data are given by the red line, whereas the blue line depicts the simulation data.

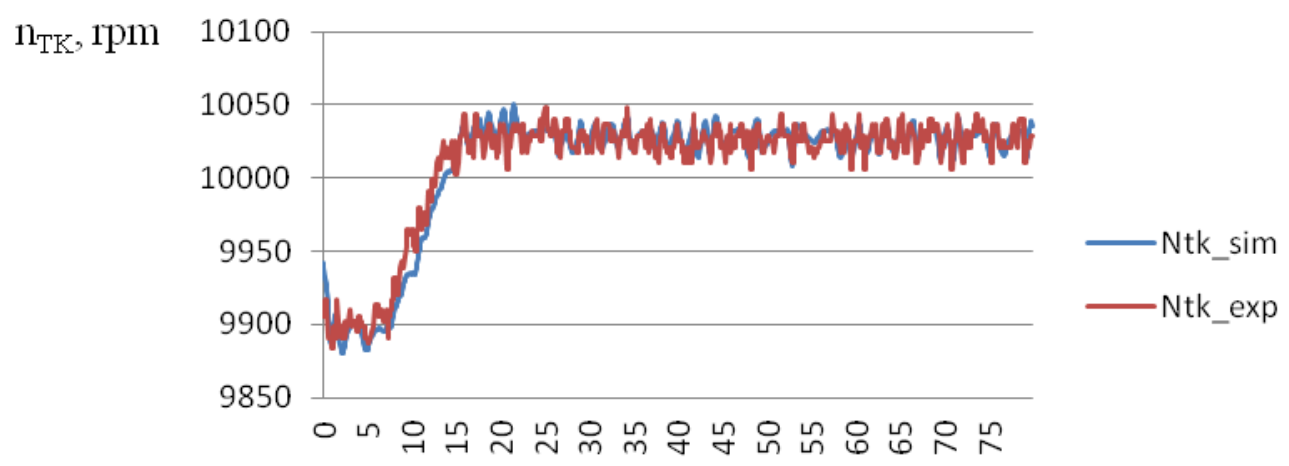

$\mathrm{t}, \mathrm{sec}$

Fig. 9. Transient state of compressor rotor speed 


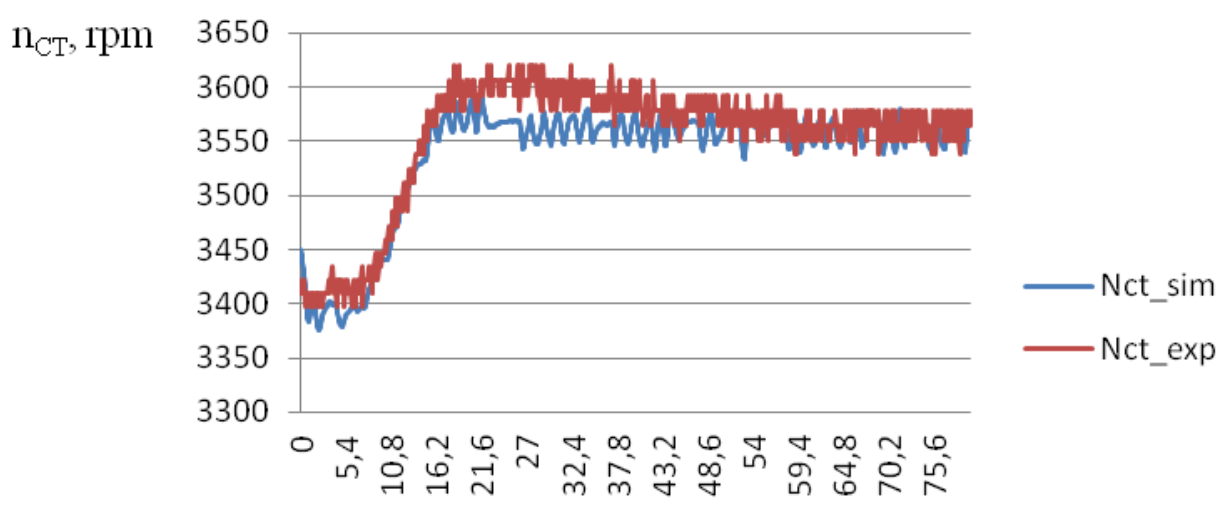

$\mathrm{t}, \mathrm{sec}$

Fig. 10. Transient state of free power turbine rotor speed

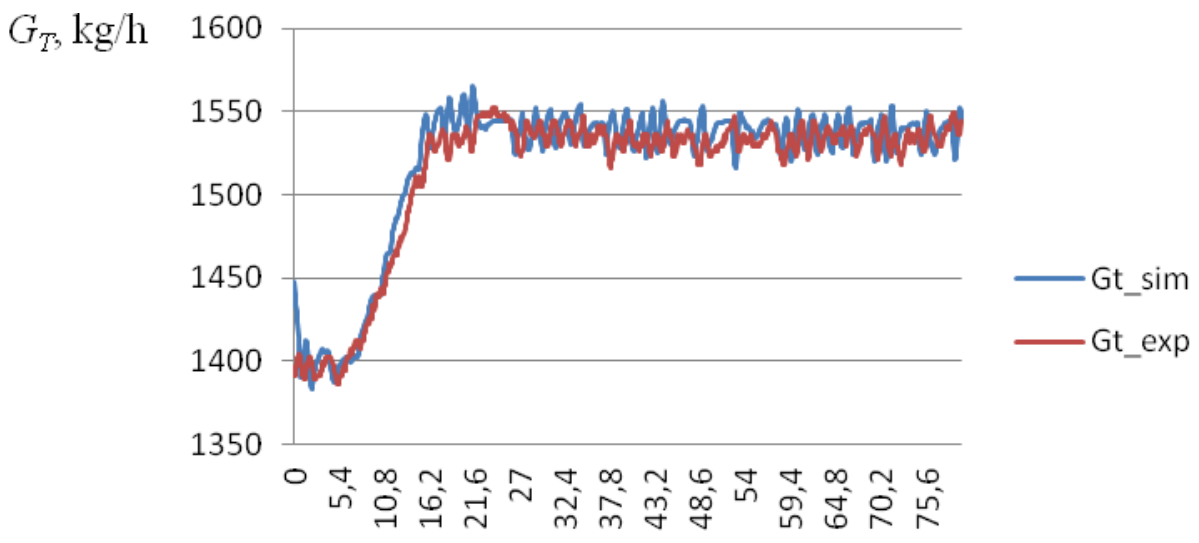

$\mathrm{t}, \mathrm{sec}$

Fig. 11. Transient state of fuel consumption

The same comparison was done for step increase and step decrease load simulation of gas pumping unit model and nonlinear Capstone microturbine model. Table 1 shows the obtained values of Theil uncertainty coefficient for all tested fast mathematical models of GTU.

Table 1.

Values of Theil uncertainty coefficient

\begin{tabular}{|l|c|c|c|}
\hline Tested model & $\mathbf{U}_{\mathbf{N T K}} \mathbf{\%}$ & $\mathbf{U}_{\mathbf{N C T}} \mathbf{\%}$ & $\mathbf{U}_{\mathbf{G T}} \mathbf{\%}$ \\
\hline Nonlinear gas pumping unit model (step increaseload) & 0,05 & 0,3 & 0,4 \\
\hline Nonlinear gas pumping unit model (step decreaseload) & 0,04 & 0,5 & 0,4 \\
\hline $\begin{array}{l}\text { Nonlinear Capstone microturbine model } \\
\text { (step increase load) }\end{array}$ & - & 0,3 & 2,2 \\
\hline $\begin{array}{l}\text { Nonlinear Capstone microturbine model } \\
\text { (step decrease load) }\end{array}$ & - & 0,4 & 2 \\
\hline
\end{tabular}

According to the results of Theil uncertainty coefficient calculation for basic compared parameters constructed fast mathematical models are reliable and have sufficient accuracy. Most of the values of Theil uncertainty coefficient does not exceed $1-2 \%$.

\section{Conclusion}

Program module for gas turbine, gas turbine ACS and electrical power system co-simulation fully satisfies all requirements and performs all the necessary functionality.

Fast mathematical models which were implemented in the module can be used for diagnostic tasks, for configuration and optimization of gas turbine control systems during various GTU testing. This enables to expand the functionality of GTU testing, to reduce the time of preparation and testing, and thus to reduce the cost of development and commissioning of gas turbines. 
In addition to the direct use of the developed module on test rigs, it is possible to use it in other research stands and automation systems, built on the basis of LabVIEW. Implemented GTUs fast mathematical models can be used as elements of power generation in the stands for computer and semi-realistic simulation of various types of energy networks based on LabVIEW for the energy network computer and semi-realistic simulation stands.

\section{Reference:}

1. Petrochenkov A. B., Kavalerov B. V., Shmidt I. A., Odin K. A., Tarasov V. A. Razrabotka metodologii i programmno-tekhnicheskikh sredstv intellektualizatsii yedinogo tsentra mnogotselevykh ispytaniy gazoturbinnykh ustanovok do 40 MV [Development of a methodology and software and hardware means of intellectualization of an integrated center for multipurpose testing of gas turbines up to 40 MW]. Perm: PNRPU, research progress report, 2012. (in Russian)

2. Kavalerov B. V., Kazantsev V. P., Shmidt I. A. Simulator and Semi-Nature Testing of GasTurbine Power Units Control Systems. Information and Control Systems, 2011, no. 4 (53), pp. 3441. (in Russian)

3. Kilin G. A., Kavalerov B. V., Odin K. A. Identifikatsiya MT Capstone dlya modelnogo ispytaniya i nastroyki sistemy upravleniya [Identification of Capstone micro turbine for model testing and control system adjustment]. Perm, 2013. (in Russian)

4. Kavalerov B. V., Petrochenkov A. B., Odin K. A., Tarasov V. A. Modeling of the Interaction of Structural Elements. Russian Electrical Engineering, 2013, vol. 84, No. 1, pp. 9- 13. available at: http:/ / link.springer.com/ article/ 10.3103/S1068371213010033

\section{(DOI: 10.3103/S1068371213010033).}

5. Petrochenkov A. B., Kavalerov B. V., Odin K. A., Arbuzov I. A., Shchenyatskiy D. V., Ryazanov A. N. "ElektroDin". Patent RF №2012660288, 2012, Rospatent.

6. Petrochenkov A. B., Kavalerov B. V., Odin K. A., Arbuzov I. A., Shchenyatskiy D. V., Ryazanov A. N. Baza dannykh ElektroDin ["ElektroDin" database]. Patent RF № 2012621177., 2012, Rospatent.

7. Vinokur V. M., Kavalerov B. V., Petrochenkov A. B., Sapunkov M. L. Matematicheskoye modelirovaniye gazoturbinnykh mini-elektrostantsiy i mini-energosistem [Mathematical modeling of gas turbine power plants and microgrids]. Perm: PNRPU publishing office, 2010. 299 p. (in Russian)

8. Vlasov V. G., Shchenyatskiy D. V. Perspectives of service development for oil and gas industry. 6 Mezhdunarodnaya nauchno-tekhnicheskaya konferentsiya "Razrabotka, proizvodstvo i ekspluatatsiya turbo-, elektronasosnykh agregatov i sistem na ikh osnove". Voronezh, 2009, 8 p.

9. Patrakeyev N. V., Potapov A. I., Makhov V. E. LabVIEW 8 - novyye vozmozhnosti avtomatizatsii proyektirovaniya kontrolno-izmeritelnykh sistem [New opportunities for design automation of measurement and control systems]. Components \& Technologies, 2007, no. 2(67), pp. 138- 141. (in Russian)

10. Ahlburg D. A. Forecast Evaluation and Improvement Using Theil's Decomposition. J ournal of Forecasting, 1984, vol. 3, no. 3, pp. 345-351.

11. Semenychev V. K., Semenychev Ye.V. Parametricheskaya identifikatsiya ryadov dinamiki: struktury, modeli, evolyutsiya [Parametric identification of the time series: structures, models, evolution]. Samara: SSC RAS, 2011, 364 p. (in Russian)

12.Waterhouse S. Comparing and simulating travel time predictions from stationary and mobile sensors. Stockholm, 2011, 65 p. 